\title{
Risk Factors and Coronary Artery Diseases in Young Adults Above and Below 40 Years: An Observational Study
}

\author{
S.D. Kadam ${ }^{1}$, Priya P. Roy ${ }^{2}$, A.B. Shelake ${ }^{3}$, M.A. Doshi ${ }^{4}$ \\ ${ }^{1}$ M.Sc, Anatomy, ${ }^{2}$ Associate Prof, Dept of Anatomy, ${ }^{3}$ Associate Professor \& HOD, Department of Cardiology, \\ ${ }^{4}$ Professor \& HOD, Department of Anatomy, Krishna Institute of Medical Sciences, Deemed to be University, \\ Karad, Maharashtra
}

\begin{abstract}
Background: Coronary artery disease and its complications are increased in young adults in developing countries. In this study we aimed to identify the risk factors and coronary angiographic profile of young adults with coronary artery disease.
\end{abstract}

Objectives: To find out the risk factors for coronary heart disease in young adults in below and above 40 years and compare the pattern of the disease .

Method: This is an observational descriptive study was conducted in Angiography Laboratory, in Krishna institute of Medical Sciences deemed to be University and Krishna Hospital, Karad. (Maharashtra) from April 2018 to July 2019. A total of about 324 patients from Angiography Laboratory of Krishna Hospital, Cardiology department were included in this study. During the procedure of coronary angiogram type of dye (OMNIPCK-50ml) that is visible by an x-ray machine (GE.INNOVA), is injected into peripheral vessels. Time taken for this procedure is 30-60 minutes.33 patients (25[75.7\%] male \& 8[24.2\%] female) were in $\leq 40$ years \& 291 patients (185[63.57\%] male \& 106[36.42\%] female) were above 40 years of age studied. Demographic data of patients and Angiographic reports were recorded.

Result: Coronary artery disease (CAD) was present in 10 patients of aged below 40 years and in 194(66.66\%) patients of age more than 40 years which comes around $66.66 \%$. Frequency of normal, Single Vessel disease, Double Vessel Disease \& Triple Vessel Disease in above $40 \mathrm{yr}$ age group was 23(69.70\%), 7(21.21\%), $2(6.06 \%)$, and $1(3.03 \%)$ respectively.

Frequency of normal, SVD, DVD \& TVD in >40 years was 97 (33.33\%), 63(21.65\%), 58 (19.93\%), and $73(25.08 \%)$ respectively. Overall 98 (27.77\%) patients were Diabetes, Hypertension was present in 160 (49.38\%), 114(35.18\%)was Smoker, Obesity were 99(30.55\%) and Family history was present in114 (35.18\%) patient, $58.76 \%$ was Tobacco user patients in $>40 y e a r s$. Frequency of Diabetes, Hypertension, Smoker, Obesity, Family history, Tobacco users in $\leq 40$ years was $12.12 \%, 36.36 \%, 5.9 \% .72 .72 \%, 39.39 \%$, $48.48 \%$ respectively.

Keywords: Coronary artery disease, Risk factors, Hypertension, Diabetes.

\section{Introduction}

\section{Corresponding Author:}

Priya P. Roy

Associate Prof, Department of Anatomy, Krishna

Institute of Medical Sciences, Deemed to be university,

Karad, Maharashtra

e-mail: priyaproy4@gmail.com

Mob.: 9970117336
The global burden of diseased study estimated that there are 31 million people with coronary artery disease in India. Approximately 1.7 million people die of cardiovascular diseases in India. ${ }^{1}$ The risk of CAD in Indians is 3-4 times higher than white Americans, 6 times higher than Chinese \& 20 times higher than Japanese. $^{2}$ 
The burden of Coronary artery disease has been on the rise in India. It is on a higher side in the urban population mainly because of their changing life style. There are many risk factors like Diabetes, hypertension, smoking, Alcohol, obesity, family history at younger age. Thus there is a need to diagnose early and thus correct the conventional risk factors. The studies revealed that $28.6 \%$ of adult aged 15 and above in India currently use tobacco. Among adult $24.9 \%$ are daily tobacco users and $3.7 \%$ are occasional users. ${ }^{3}$ Many younger's migrate from rural to urban for jobs. It is associated with stress of seeking, stress of adjusting new job, stress of new friend circles. They undergoing to facing many problem like the higher consumption of calories, intake of saturated fats,salts,alcohol and mainly the products of tobacco. Products of tobacco like the smoking, tobacco chewing, mishary using increases the risk of CAD. These are the risk factors to indicate the Hypertension, Diabetes, and Obesity. Use of multiple tobacco products as cigarettes, mishary is common among young age. The nicotine and carbon monoxide from smoking may make your blood sticky and arteries become narrow. Narrow arteries reduce the flow of blood to your heart, muscle.

Smoking increases the risk of CAD by 3-5 times. In India smoking is increasing in the younger generation. Studies have shown that $40-50 \%$ of males in obesity is the next risk the increase body fat is the increases the risk. ${ }^{2}$ In an analysis of worldwide data for the global burden of hypertension, $20.6 \%$ of Indian men and $20.9 \%$ of Indian women were suffering from hypertension in 2005. The rates for hypertension in percentage are projected to go up to $22.9 \& 23.6$ for Indian men \& women respectively by $2025 .{ }^{4}$

Diabetes mellitus is one of the world's major diseases and also increases the risk of cardiovascular diseases. It currently affects an estimated 143 million people worldwide $\&$ the number is growing rapidly. In India, about $5 \%$ population suffers from diabetes. ${ }^{5}$

The incidence of CAD in young Indians is about $12 \%-16 \%{ }^{6}$ So this study was done to identify and compare the differences of risk factors of CAD in $\leq 40$ year and $>40$ year patients.

\section{Material and Method}

This is an observational descriptive study and was conducted in Cardiology Laboratory in Krishna Institute of Medical Sciences deemed to be University and Krishna Hospital, Karad (Maharashtra). The study period was from April 2018 to July 2019. A total of about 324 patients from undergoing angiography from Cardiology department, were included in the study. Demographic and anthropometric data of study cases will be obtained from IPD records as well as by interviewing the patient. Angiographic variables and coronary parameters will be measured with help/guidance/assistant of cardiologists.

Demographic Data Collected of Patient: The data noted from patients are Age, Gender, Religion, Occupation,Body weight, Height, Body surface area, Diabetes, Hypertension, Chest pain, Smoking, Family history, Exercise, Tobacco chewing, Diet, Alcohol consumption.

Exclusion Criteria: Patients with previous history of coronary artery intervention (balloon or stenting) patients with previous history of coronary artery bypass graft surgery.

Methodology of Coronary angiography- During the procedure of coronary angiogram type of dye (OMNIPCK-50ml) that is visible by an $\mathrm{x}$-ray machine (GE.INNOVA), is injected into peripheral vessels. Time taken for this procedure is $30-60$ minutes and cineangiogram were taken in different views.

The procedure of research was explained to the patients and written consent form was taken from each participants present to enrolment in the study. Then Demographic information recorded on a Questionnaire. Coronary angiography was performed by Cardiologists. All patients were evaluated for coronary risk factor like Diabetes, hypertension, smoking, alcohol, obesity, family history.

The Normal, Single vessel Disease (SVD), Double vessel disease (SVD), Triple vessel disease (TVD) was noted and confirmed by report given by cardiologist . The data were entered in SPSS Version. Pattern of coronary involvement and risk factors were noted.

\section{Results}

Table 1: Age wise distribution of patients:

\begin{tabular}{|l|c|c|c|}
\hline Gender & $\begin{array}{c}\text { <40 years } \\
\text { No (\%) }\end{array}$ & $\begin{array}{c}>41 \text { years } \\
\text { No (\%) }\end{array}$ & Total No (\%) \\
\hline Male & $25(75.7)$ & $185(63.57)$ & $210(64.81)$ \\
\hline Female & $8(24.2)$ & $106(36.42)$ & $114(35.18)$ \\
\hline Total & $33(10.18)$ & $291(89.81)$ & $324(100)$ \\
\hline
\end{tabular}

The total number of patients included in this study 
was 324. The patients were divided into two groups. The group I were the patients who were $\leq 40$ year of age. The patients in group II were above 40 years of age. Out of $324,33(10.18 \%)$ were $\leq 40$ were in group I and $291(89.81 \%)$ were in group II. The youngest patient was 22 years of age $\&$ eldest was 87 years of age. The mean age in $\leq 40$ years (Group I) was 33.96 year $\&>40$ years (Group II) was 61.17 year.

In group I ( $\leq 40$ years) there were $25(75.7 \%)$ male $\& 8(24.2 \%)$ were female, in group II ( $>40$ years) there were $185(63.57 \%)$ males \& $106(36.42 \%)$ were females. (Table I).

Table 2: Age \& sex wise distribution of Risk Factors

\begin{tabular}{|c|c|c|c|c|}
\hline \multirow[b]{2}{*}{ Risk Factors } & \multicolumn{2}{|c|}{$\leq 40$ yrs. $(n=33)$} & \multicolumn{2}{|c|}{$>41$ yrs. $(n=291)$} \\
\hline & $\begin{array}{c}\text { Male no. }(\%) \\
\text { 25(75.7) }\end{array}$ & $\begin{array}{c}\text { Female no. }(\%) \\
8(24.2)\end{array}$ & $\begin{array}{c}\text { Male no. (\%) } \\
185(63.57)\end{array}$ & $\begin{array}{c}\text { Female no. (\%) } \\
\text { 106(36.42) }\end{array}$ \\
\hline Diabetes & $2(8)$ & $2(25)$ & $56(30.27)$ & $38(35.85)$ \\
\hline Hypertension & $10(40)$ & $2(25)$ & $88(47.57)$ & $62(54.38)$ \\
\hline Smoking & $2(8)$ & 0 & $20(10.81)$ & 0 \\
\hline Family history & $11(44)$ & $2(25)$ & $60(32.43)$ & $41(38.68)$ \\
\hline Tobacco user & $14(56)$ & $2(25)$ & $110(59.46)$ & $61(57.55)$ \\
\hline \multicolumn{5}{|l|}{ BMI } \\
\hline $18.5-24.9$ & $6(24)$ & $73(40.10)$ & $3(37.5)$ & $54(53.46)$ \\
\hline $25-29.9$ & $9(36)$ & $78(42.86)$ & $4(50)$ & $32(31.68)$ \\
\hline $30 \&$ Above & $10(40)$ & $31(17.03)$ & $1(12.5)$ & $15(14.85)$ \\
\hline
\end{tabular}

Regarding coronary risk factors, Presence of diabetes was higher in the patients $>40 y$ rs. Patients was $94(32.30 \%)$ than that in $\leq 40$ years patients ie. 4(12. 12\%).Hypertension was significantly less in $\leq$ 40 years $12(36.36 \%)$ than that in the $>40$ years group $150(51.55 \%)$.

2 patients $(6.06 \%)$ of in $\leq 40$-year group were smoker as compare to $20(6.87 \%)$ in $40>$ years group. Higher incidence of obesity was observed in $72.72 \%$ in $\leq 40$-year group than in $>40$ year group $99(30.55 \%)$
Presence of family history of coronary heart disease was observed in $\leq 40$ year group $14(42.42 \%)$ than that in $>40$ years ie. $101(34.71 \%) .16$ patients $(48.48 \%)$ of $\leq$ 40 years were tobacco user as compare to $171(58.76 \%)$ in $>40$-year group. The most prevalent cardiovascular risk factors was tobacco users $(48.48 \%)$ in $\leq 40$ years $\&$ $171(58.76 \%)$ in $>40$-year group \& increased body mass index $>25 \mathrm{Kg} / \mathrm{m}^{2}$, followed by a family history of CAD $\&$ Hypertension, The proportion of patients with obesity with family history of coronary heart disease was high in $\leq 40$-year group $(72.72 \% \& 39.39 \%)$ respectively. (Table 2).

Table 3: Showing Comparison of Risk Factors with other author

\begin{tabular}{|c|c|c|c|c|c|c|}
\hline \multirow{2}{*}{ Risk Factors } & $\leq 40 \mathrm{yrs}$ & >41yrs. & $\leq 40 \mathrm{yrs}$ & $>41$ yrs. & $\leq 40$ yrs. & $>41 \mathrm{yrs}$ \\
\hline & \multicolumn{2}{|c|}{ Tahir Saghir $^{7}$ et al No. (\%) } & \multicolumn{2}{|c|}{ Md.Abu Siddique ${ }^{8}$ et al No. (\%) } & \multicolumn{2}{|c|}{ Present study No. (\%) } \\
\hline No. of patient & $102(34)$ & 197(66) & $50(50)$ & $50(50)$ & $33(10.18)$ & $291(89.81)$ \\
\hline Mean age & - & - & 33.0 yrs. & $52.0 \mathrm{yrs}$. & 33.96 yrs. & 60.88 yrs. \\
\hline Diabetes & $14(14)$ & $71(36)$ & $2.0(4.0)$ & $17.0(34.0)$ & $4(12.12)$ & $94(31.65)$ \\
\hline Hypertension & $35(34)$ & $83(42)$ & $19.0(38.0)$ & $36.0(72.0)$ & $12(36.36)$ & $150(51.54)$ \\
\hline Smoking & $71(70)$ & $148(75)$ & $35.0(70.0)$ & $23.0(46.0)$ & $2(6.06)$ & $20(6.87)$ \\
\hline Family history & $3(30)$ & $52(26)$ & $18(36.0)$ & $8(16.0)$ & 13(39.39) & $101(34.70)$ \\
\hline \multicolumn{7}{|l|}{ BMI } \\
\hline $18.5-24.9$ & $31(31)$ & $60(31)$ & -- & -- & $9(27.27)$ & $127(43.64)$ \\
\hline $25-25.9$ & $55(53)$ & $10(51)$ & -- & -- & $13(39.39)$ & $110((37.80)$ \\
\hline $30 \&$ Above & $16(16)$ & $36(18)$ & -- & -- & $11(33.33)$ & $46(15.81)$ \\
\hline
\end{tabular}


Table 4: Showing Coronary Artery Disease and Age.

\begin{tabular}{|l|c|c|}
\hline Coronary Artery Disease & $\mathbf{4 0 - y e a r}(\mathbf{n}=\mathbf{3 3})$ No. $(\mathbf{\%})$ & $>$ 40 year(n=291) No. $(\mathbf{\%})$ \\
\hline Normal & $23(69.70)$ & $97(33.33)$ \\
\hline SVD & $7(21.21)$ & $63(21.65)$ \\
\hline DVD & $2(6.06)$ & $58(19.93)$ \\
\hline TVD & $1(3.03)$ & $73(25.08)$ \\
\hline
\end{tabular}

SVD-single vessel disease DVD-double vessel disease TVD-triple vessel disease

Table 4 shows distribution of coronary artery disease according to age.

Coronary artery disease (CAD) was present in $10(30.3 \%) \leq 40$ years and in $194(66.66 \%)$ patients $>40$ years. Frequencies of normal, SVD, DVD, \& TVD in $\leq 40$ was $23(69.70 \%), 7(21.21 \%), 2(6.06), 1(3.03 \%)$ respectively. while frequencies' of normal, SVD, DVD, TVDIN $>40$ was $97(3 \mathrm{~N} 3.33 \%), 63(21.65 \%), 58(19.93 \%)$, $73(25.08 \%)$ respectively.

\section{Discussion}

In the present scenario death due to cardiovascular diseases has been increased from 1.3 million in 1990 to 2.8 million in $2016 \&$ more than half the deaths caused by heart disease in 2016 were in persons less than 70 years of age, according to the study 'The changing Pattern of cardiovascular diseases $\&$ their risk factors in the states of India ' the Global burden of Disease study, $15 \%$ of deaths in India were due to heart disease in 1990 , now up to $28 \%{ }^{9}$

In this study we included 324 patients. Out of total 324 patients 33 are less than 40 years $(10.18 \%) \& 299$ are above 40 years $(89.81 \%)$.Hazrat Ullah Khan et al ${ }^{10}$ was done the study in 2014, in which frequencies of age $\leq 40$ year $\&>40$ year were $48(12 \%) \& 352(88 \%)$. Mean age of the patient was 55.27 which is similar as determined by Hazrat ${ }^{10}$ and was 52.78 . Table -3 shows comparison of risk factors in different studies.

In this study Frequencies of diabetes, Hypertension, Smoking, Obesity, Family history \& Tobacco user were 98(27.27\%),160(49.38\%),114(35.18\%),99(30.55\%) ,114(35.18\%),58.76\%in $>40$ year. $\& \leq 40$ years was $12.12 \%, 36.36 \%, 5.9 \%, 72.72 \%, 39.39 \%, 48.48 \%$, which is nearly same as by Tahir Saghir.

Significant CAD was present in 10(30.3\%) patient of $\leq 40$ yrs. Patients \& in $194(66.66 \%)$ patient of $>40$ year. Total $63.63 \%$ of CAD wasp resent which is nearly same as by Aknd which $74.4 \% .{ }^{10}$ In our study the Family history for CAD is present was present in $39.39 \%$ in $\leq 40$ yrs. Patients \& $35.18 \%$ was in $>40$ yrs. But Tahir Saghirs et al study shows $3(30 \%)$ in $\leq 40$ yrs. Patients $\&$ $52(26 \%)$ in $>40$ yrs. patients. The data for western world showing family history present in $45-65 \%$ of $\leq 40 \mathrm{yrs}$. \& $20-40 \%$ in $>40$ yrs.

This study showed frequencies of normal, SVD, DVD, \& TVD in $\leq 40$ was $23(69.70 \%), 7(21.21 \%)$, 2(6.06), 1(3.03\%) respectively. while frequencies of normal, SVD, DVD, TVD in $>40$ was $97(33.33 \%)$, 63(21.65\%), 58(19.93\%), 73(25.08\%) respectively. Shah S Set al $^{11}$ studied that $\leq 40$ years patients have frequencies of SVD, DVD, \& TVD shows $44.4 \%$, $24.4 \% \& 15.6 \%$ \& in $>40$ years group has $25.4 \%, 30.5 \%$ $\& 39.4 \%$ respectively. Siddque Met $\mathrm{al}^{8}$ studied that $\leq 40$ years group has frequencies of SVD, DVD, \& TVD as $42 \%, 22 \%, \& 18 \% \&$ in $>40$ yrs. were $24 \%, 24 \% \& 46 \%$ resp.

\section{Conclusion}

In conclusion the young patient $(\leq 40 \mathrm{yrs}$.) have different risk factor in comparison with elder group $(>40$ yrs.) Tobacco user including smoking is a common risk factor in the patients. Risk factors in CAD patient is threat for $\leq 40$ yrs. group. We will advise to these people to live in healthy life style and precautions about tobacco products should be taken. This study will definitely benefit to younger group. The rate of CAD risk factors in $\leq 40 \mathrm{yrs}$. is high. Most important risk factor is Tobacco users \& Obesity.

So there should be needed more visible and aggressive anti-tobacco camps including increased public awareness of tobacco harms and active arrangement of workshops. It should be helpful to younger age group.

Limitation: Some other risk factors may also be contributing to the coronary artery diseases. 
Ethical Considerations: The present study was approved by the Institution Ethical Committee KIMS "Deemed To Be University", Karad.

Conflicts of Interest: None.

Source of Funding: KIMS "Deemed To Be University", Karad.

\section{References}

1. https://www.csikerala.org/ACS $\% 20$ Registry $\% 20$ -\%20Project\%20Report.pdf Kerala Acute Coronary Syndrome Registry Project Report

2. HS Rissam, S Kishore, N Trehan, Coronary Artery Disease in Young Indians-The Missing Link. Journl Indian Academy of Clinical Medicine, 2001; Vol.2(3) : 128-132.

3. https://www.who.int/tobacco/surveillance/en_tfi_ india_gats_fact_sheet.pdf, GATS

4. Raghupathy Anchala, Nanda K, Kannuri, \& DorairajPrabhkaran-Hypertension in India: a systematic review \& metanalysis \& control of hypertension. Journal of Hypertension, 2014; 32 (6): 1170-7.

5. https://bit.ly/32UAth4. (Om) life style. India is the diabetes capital of the world-Times of India

6. G Suresh, K Subramanym, SrinivasaKudva, Ram Prakasha Saya. Coronary artery disease in young adults: Angiographic study-A single center experience. Heart India 2016;4:132-5.

7. Tahir Saghir, NadeemQamar, JavaidSial;Coronary Angiographic Characteristics of coronary Artery Disease in Young Adults Under Age Forty Years Compare to Those Over Age Forty. Pakistan Heart Journal, 2008; Vol. 41 (3): 49 - 56 .

8. Md.AbuSiddique, Milan Prakash Shrestha, Mohammad Salman, KMHSSirajuHaque, Md. KhurshedAhmed, Md.Ashraf Uddin Sultan, Md. HarisulHoque, SM. Mustafa Zamau.Age- Related Differences of Risk Profile and Angiographic Finding in Patients with Coronary Heart Disease. BSMMU J, 2010; Vol.3 (1) :13-17.

9. https://bit.ly/31TTnTZ .ToufiqRshid $15 \%$ of deaths in India were due to heart diseases in 1990; now up to $28 \%$.

10. Hazrat Ullah Khan, Mati U Khan, Md Munir Noor, Umer Hayat, Muhammad Adeel Alam. Coronaryartery Disease Pattern: A Comparison among Different Age Groups. J Ayub Med Coll Abbottabad 2014;26(4) : 466-9.

11. Shah SS, Noor L, Shah SH, Shahsawar, Awan ZA, et al. Myocardial Infarction in Young verus older Adults: Clinical characterstics and Angiographic features. J Ayub Med Coll Abbottabad,2010; 22 (2):187-90. 